\title{
Survival and Treatment Outcomes in Patients with Extracranial Oligometastatic Breast Cancer: Single-Center Experience
}

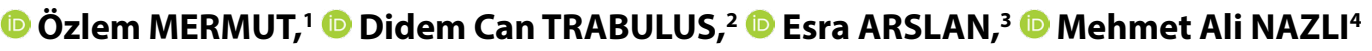 \\ 'Department of Radiation Oncology, Health Sciences University, İstanbul Education and Research Hospital, İstanbul-Turkey \\ ${ }^{2}$ Department of General Surgery, University of Health Sciences, İstanbul Education and Research Hospital, İstanbul-Turkey \\ ${ }^{3}$ Department of Nuclear Medicine, University of Health Sciences, İstanbul Education and Research Hospital, İstanbul-Turkey \\ ${ }^{4}$ Department of Radiology, Health Sciences University, İstanbul Education and Research Hospital, İstanbul-Turkey
}

\begin{abstract}
OBJECTIVE
Oligometastatic tumors are usually characterized by a solitary or small number of metastatic lesions confined to a single organ. This study aims to investigate the prognostic factors for overall survival in patients with extracranial oligometastatic breast cancer and share our own experiences.
\end{abstract}

\section{METHODS}

We evaluated 130 patients who were admitted for the diagnosis of extracranial oligometastatic breast cancer at the University of Health Sciences Istanbul Training and Research Hospital Department of Radiation Oncology between 2013 and 2017.

\section{RESULTS}

Age ( $\mathrm{p}=0.003)$, type of surgery $(\mathrm{p}<0.001)$, estrogen receptor status positivity $(\mathrm{p}=0.011)$, location of metastasis $(\mathrm{p}<0.001)$, premenopausal status $(\mathrm{p}=0.001)$, number of metastases $(\mathrm{p}=0.029)$, administration of chemotherapy $(\mathrm{p}<0.001)$ and application of curative radiotherapy $(\mathrm{p}<0.001)$ were the prognostic factors affecting overall survival in univariate analysis. Age $<50$ (HR: 5.434; $95 \%$ CI: 1.025-28.80; $\mathrm{p}=0.047$ ), only bone metastasis (HR: 0.165; 95\% CI: $0.073-0.370$; $\mathrm{p}<0.001$ ), premenopausal status (HR: 0.125 ; $95 \% \mathrm{CI}$ : $0.022-0.723 ; \mathrm{p}=0.020$ ) and chemotherapy administration (HR: $4.342 ; 95 \%$ CI: $1.792-10.52 ; \mathrm{p}=0.001$ ) were independent prognostic factors that positively affected overall survival in multivariate analysis.

\section{CONCLUSION}

Oligometastatic breast cancer is a separate subgroup with long-term prognosis for patients with metastatic breast cancer. In patients with extracranial oligometastatic breast cancer, long-term disease control may be possible using more aggressive multidisciplinary treatments, particularly in patients with bone-only metastases.

Keywords: Breast cancer; oligometastases; survival. Copyright $\odot$ 2020, Turkish Society for Radiation Oncology

\section{Introduction}

Metastatic breast cancer is often viewed as incurable, and its 5-year survival rate is $27 \%$.[1] Oligometastatic tumors are usually characterized by a solitary or small number of metastatic lesions confined to a single organ.[2] The guidelines of the fourth ESO-ESMO International Consensus have expanded the definitions 
of oligometastatic disease from a single organ to a limited number of metastatic lesions, with low-level metastatic disease (up to five lesions, and not always in the same organ).[3] Stage IV disease is observed in approximately $1 \%-10 \%$ of patients with newly discovered metastatic breast cancer.[4-7] However, it is not evident which subgroups of patients with metastatic breast cancer would benefit from surgery of the primary lesion. Treatment objectives for stage IV disease are prolongation of survival, control of tumor burden, reduction of cancer-related symptoms, and preservation of the quality of life. Therefore, this study aims to describe the prognostic factors for overall survival in patients with extracranial oligometastatic breast cancer (OMBC).

\section{Materials and Methods}

We enrolled 130 patients with extracranial breast cancer who were evaluated at the University of Health Sciences Istanbul Training and Research Hospital Radiation Oncology clinic between 2013 and 2017. Exclusion criteria included patients who were under 18 years of age, male sex and those with another solid or hematological tumor or brain metastases. All patients underwent positron emission tomography-computed tomography to perform staging before diagnosis. The last patient follow-up was in December 2018. We conducted 6-8 cycles of chemotherapy or hormonotherapy (if chemotherapy could not be used), administered bisphosphonates, and/ or performed palliative radiotherapy (300 cGy/day doses in 10 fractions for bones). We didn't have a radiosurgery group. The response to treatment was assessed according to the Response Evaluation Criteria in Solid Tumors guidelines version 1.1.[8] Patients who had a complete response were operated by a surgeon. Radiotherapy was performed for the operated breast and then, according to hormone receptor status, adjuvant hormonotherapy was initiated. Overall survival (OS) was defined as the time until death. Progression-free survival was defined as the time from the initiation of treatment to the point when disease progression was detected. This retrospective study was approved by the ethics committee of our hospital (number: 2019/1893).

\section{Statistical Analysis}

For descriptive statistics of the data, average, standard deviation, median, lowest, highest, frequency, and ratio values were used. The distribution of variables was measured using the Kolmogorov-Smirnov test. The MannWhitney U test was used for the analysis of quantitative independent data, whereas the chi-square test was used for the analysis of qualitative independent data. Fischer's exact test was used when chi-square test conditions were not provided. Survival analysis was performed using the Kaplan-Meier (log-rank) test, Cox model for univariate and multivariate analysis. The SPSS 22.0 (IBM SPSS, Armonk, NY, USA) program was used for analyses. A pvalue $<0.05$ was considered significant.

\section{Results}

The median age of the patients was 52 (27-86 years). The most commonly observed histological type of breast cancer was invasive ductal carcinoma $(80 \%$, $\mathrm{n}=104)$. The mean diameter of the tumor was 3.8 $\mathrm{cm}(1-15 \mathrm{~cm})$. Fifty-six percent $(\mathrm{n}=72)$ of the patients were postmenopausal, $44 \%(n=58)$ were premenopausal. Palliative radiotherapy was administered to $62 \%(n=81)$ of the patients. No statistical significance was observed between survival analysis groups concerning tumor diameter, histology, nuclear grade, progesterone receptor status, c-erbB2 receptor status, KI-67 ratio and $\mathrm{T}$ (tumor) or $\mathrm{N}$ (lymph node) stages. A second progression was observed in $14.6 \%$ of patients after an average of 6.7 months, and the next most common sites of metastases were bone $(n=7 ; 5.4 \%)$, liver $(n=6 ; 4.6 \%)$, brain $(n=5 ; 3.8 \%)$, and lung $(n=1 ; 0.8 \%)$ in patients $(\mathrm{p}=0.007)$. The general characteristics of the patients are shown in Table 1.

Seven patients who could not undergo chemotherapy were $\geq 80$ years of age. Three of them were young and they only underwent palliative radiotherapy and hormonotherapy. However, due to disease progression, they survived for $<6$ months. Curative radiotherapy was applied to 28 patients with modified radical mastectomy (MRM) and 13 patients underwent breastconserving surgery (BCS). There were 15 patients with MRM and only palliative radiotherapy was administered to them. Adjuvant radiotherapy was not applied to five patients who underwent MRM; they were $>70$ age. One patient was dead in the early postoperative period. Nine postmenopausal patients had T1-2N1M1, $\mathrm{ER}(+), \mathrm{PR}(+)$, CerbB2 (-) disease at initial diagnosis. Curative postmastectomy radiotherapy was not performed to these patients because of their good risk factors. Curative radiotherapy was not performed for any of the biopsy patients. Sixty-six (92\%) patients performed palliative radiotherapy; six (8\%) patients did not apply radiotherapy at all. Three of the patients without radiotherapy had only liver metastasis, while five patients had bone metastasis in painless, non-lytic, non-fracture risk localizations (e.g., ribs) (Table 2). 


\begin{tabular}{|c|c|c|}
\hline & Number of patients & $\%$ \\
\hline \multicolumn{3}{|l|}{ Location of metastases } \\
\hline Bone & 109 & 84 \\
\hline Lung, liver & 21 & 16 \\
\hline \multicolumn{3}{|l|}{ Histology } \\
\hline IDC & 104 & 80 \\
\hline ILC & 18 & 14 \\
\hline IMPC & 5 & 4 \\
\hline Apocrine & 3 & 2 \\
\hline \multicolumn{3}{|l|}{ Operation type } \\
\hline MRM/BCS & 58 & 45 \\
\hline Biopsy & 72 & 55 \\
\hline \multicolumn{3}{|l|}{ Nuclear grade } \\
\hline 1 & 5 & 4 \\
\hline$॥$ & 71 & 55 \\
\hline III & 54 & 41 \\
\hline \multicolumn{3}{|l|}{ T stage } \\
\hline $1-2$ & 103 & 79 \\
\hline $3-4$ & 27 & 21 \\
\hline \multicolumn{3}{|l|}{$\mathrm{N}$ stage } \\
\hline 1 & 37 & 28 \\
\hline 2 & 71 & 55 \\
\hline 3 & 22 & 17 \\
\hline \multicolumn{3}{|l|}{ Estrogen receptor } \\
\hline Positive & 96 & 74 \\
\hline Negative & 34 & 26 \\
\hline \multicolumn{3}{|l|}{ Progesterone receptor } \\
\hline Positive & 111 & 86 \\
\hline Negative & 19 & 14 \\
\hline \multicolumn{3}{|l|}{ CerbB2 } \\
\hline Positive & 25 & 19 \\
\hline Negative & 105 & 81 \\
\hline \multicolumn{3}{|l|}{ Chemotherapy } \\
\hline Absent & 10 & 8 \\
\hline $\mathrm{CT}+$ Trastuzumab & 25 & 19 \\
\hline 6 cycle FEC & 59 & 45 \\
\hline $4 \mathrm{AC}+4$ Docetaxel & 27 & 21 \\
\hline 6 cycle TAC & 9 & 7 \\
\hline \multicolumn{3}{|l|}{ Radiotherapy } \\
\hline Absent & 8 & 6 \\
\hline 50/60 Gy & 41 & 32 \\
\hline 30 Gy (palliative) & 81 & 62 \\
\hline \multicolumn{3}{|l|}{ Hormonotherapy } \\
\hline Absent & 18 & 13 \\
\hline Present & 112 & 87 \\
\hline \multicolumn{3}{|l|}{ Menopausal status } \\
\hline Premenopause & 58 & 44 \\
\hline Postmenopause & 72 & 56 \\
\hline \multicolumn{3}{|l|}{ Number of metastases } \\
\hline $1-2$ & 53 & 41 \\
\hline 3-5 & 77 & 59 \\
\hline
\end{tabular}

\begin{tabular}{|ccc|}
\hline Table 1 & Cont. & \\
& Number of patients & $\%$ \\
\hline KI 67 ratio & & \\
$0-14$ & 20 & 15 \\
$>15$ & 110 & 85 \\
Second metastases & & \\
$\quad$ Absent & 111 & 86 \\
Present & 19 & 14 \\
\hline
\end{tabular}

IDC: Invasive ductal carcinoma; ILC: Invasive lobular carcinoma; IMPC: Invasive micropapillary carcinoma; MRM: Modified radical mastectomy; BCS: Breast-conserving surgery; CT: Chemotherapy; FEC: 5-Fluorourasil Epirubicine Cylclophosphamide; AC: Adriablastine Cylclophosphamide; TAC: Docetaxel Adriablastine Cylclophosphamide

According to palliative radiotherapy, the absence of radiotherapy was not found to be statistically significant ( $\mathrm{p}=0.672$ ). According to palliative radiotherapy, performed curative radiotherapy was found to be statistically significant $(\mathrm{p}<0.001)$. Lastly, estimated survival time was 55 (95\% CI: 43.29-66.70) and 30 (95\% CI: 20.41-39.58) months for radiotherapy application curative and palliative groups (Log-rank $\mathrm{p}=0.001$ ). Radiotherapy absent group's survival time was 41 months. The 5-year OS for radiotherapy application groups is shown in Figure 1.

The estimated survival time was 55 and 13 months for the bone metastasis and organ metastasis groups (Log-rank $\mathrm{p}<0.001$ ), respectively. The 5-year OS for the bone metastasis and organ metastasis groups are shown in Figure 2.

Age $\leq 50$, type of surgery, estrogen receptor (ER) status positivity, location of metastasis, number of metastases, premenopausal stage, radiotherapy and chemotherapy administration were the prognostic factors affecting OS in univariate analysis (Table 3 ).

Multivariate analysis revealed that age $\leq 50$ $(\mathrm{p}=0.047)$, only bone metastasis $(\mathrm{p}<0.001)$, premenopausal status $(\mathrm{p}=0.020)$ and chemotherapy administration $(\mathrm{p}=0.001)$ were independent prognostic factors affecting OS (Table 4).

Table 2 Radiotherapy application according to operation types

\begin{tabular}{lccc} 
Radiotherapy & $\begin{array}{c}\text { MRM/BSC } \\
\text { number (\%) }\end{array}$ & $\begin{array}{c}\text { Biopsy } \\
\text { number (\%) }\end{array}$ & p \\
\hline Curative (50/60Gy) & $28 / 13(71)$ & - & \\
Palliative (30 Gy) & $15 / 0(26)$ & $66(92)$ & $<0.001$ \\
Absent & $2(3)$ & $6(8)$ & \\
\hline
\end{tabular}

MRM: Modified radical mastectomy; BCS: Breast-conserving surgery 
Table 3 Univariate Cox regression analysis

\begin{tabular}{|c|c|c|c|}
\hline Univariate analysis & HR & $95 \% \mathrm{Cl}$ & $\mathbf{p}$ \\
\hline Age $(\leq 50$ vs. $>50)$ & 0.421 & $0.236-0.751$ & 0.003 \\
\hline Operation type (MRM/BCS vs. biopsy) & 0.368 & $0.205-0.661$ & $<0.001$ \\
\hline Estrogen receptor (positive vs. negative) & 2.062 & $1.184-3.591$ & 0.011 \\
\hline Location of metastasis (bone vs. organ) & 0.281 & $0.150-0.526$ & $<0.001$ \\
\hline Number of metastases (1-2 vs. $3-5)$ & 0.531 & $0.300-0.938$ & 0.029 \\
\hline Menopausal status (premenopause vs. postmenopause) & 0.374 & $0.204-0.684$ & 0.001 \\
\hline Chemotherapy (present vs. absent) & 4.538 & $2.267-9.084$ & $<0.001$ \\
\hline Radiotherapy (palliative vs. absent) & 1.227 & $0.477-3.155$ & 0.672 \\
\hline (palliative vs. curative) & 0.122 & $0.044-0.337$ & $<0.001$ \\
\hline
\end{tabular}

MRM: Modified radical mastectomy; BCS: Breast-conserving surgery

Table 4 Multivariate Cox regression analysis

\begin{tabular}{lccc} 
Multivariate analysis & HR & $\mathbf{9 5 \%} \mathbf{C l}$ & $\mathbf{p}$ \\
\hline Age $\leq 50$ & 5.434 & $1.025-28.80$ & 0.047 \\
Location of metastasis (bone) & 0.165 & $0.073-0.370$ & $<0.001$ \\
Menopausal status (premenopausal) & 0.125 & $0.022-0.723$ & 0.020 \\
Chemotherapy (present) & 4.342 & $1.792-10.52$ & 0.001 \\
\hline
\end{tabular}

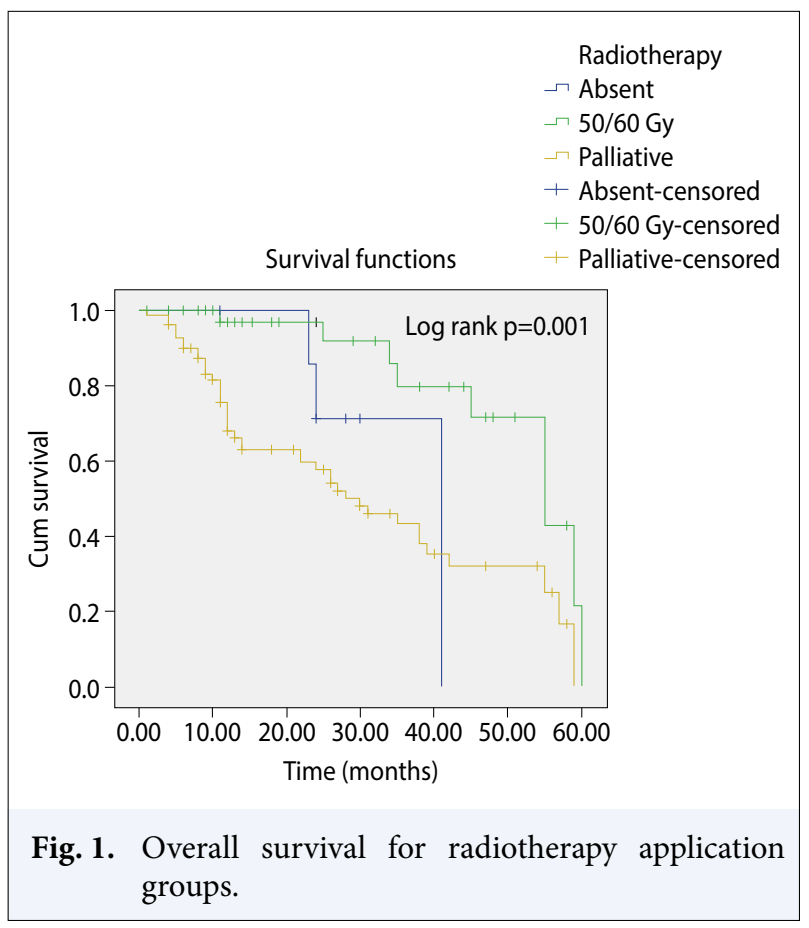

\section{Discussion}

Advances in imaging techniques have enabled the rapid detection of OMBC. Providing local treatment for OMBC is important to extend survival and control the disease.[9] In our study, the SBRT/SABR technique

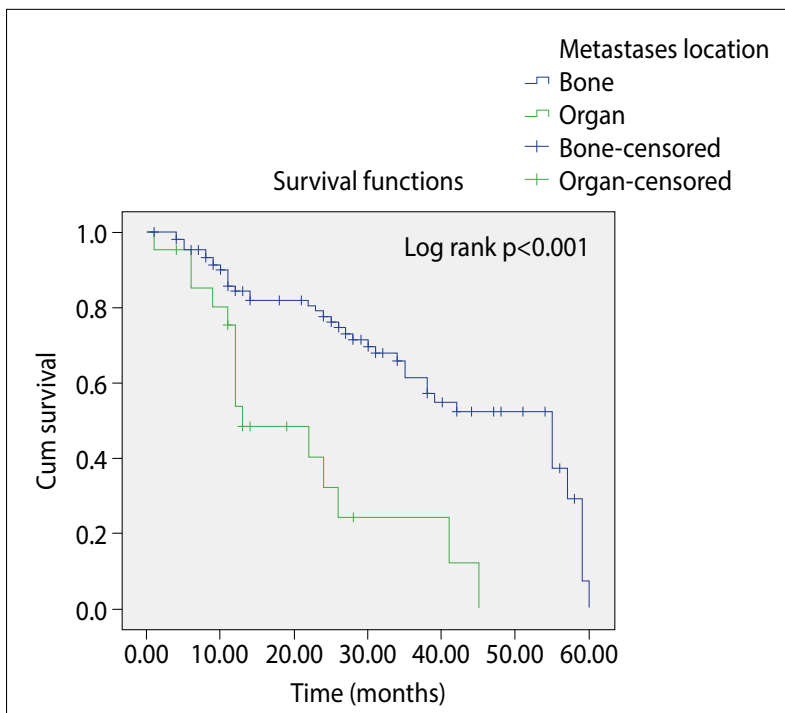

Fig. 2. Overall survival for bone and organ metastasis.

was not used for radiotherapy because our linear accelerator devices were not suitable for this. Therefore, we used 3-dimensional conformal radiotherapy, intensity-modulated radiation therapy (IMRT) or volumetric modulated arc therapy for radiotherapy. Furthermore, patients with liver and lung metastases were not eligible for metastasectomy because they had multiple organ metastases. For this group, only systemic chemo- 
therapy was used. Anthracycline-based chemotherapy was administered to $92.3 \%$ of patients.

Some patients with OMBC may benefit from surgery of the primary tumor because it leads to the eradication of the source of metastatic seeding, regeneration of immune capacity, and reduction in chemoresistance by decreasing the number of clones. $[2,10]$ Therefore, in some studies, surgical operation of the primary tumor is suggested for patients with OMBC who are less than 45 years of age.[11] The rate of operable patients was $44.6 \%$ in our study, and operation type was found to be a significant prognostic factor in univariate analysis.

Some researchers have suggested that OMBC may signify less aggressive tumor behavior and be potentially curable with aggressive treatment of the limited metastases.[12] Therefore, it should be treated using a multidisciplinary approach before the spread of cancer cells. We make decisions in the multidisciplinary breast council on the treatment of these patients in our hospital.

In breast cancer metastasis, the bone, lung, liver, and brain are considered the primary target sites. Bone metastasis occurs in approximately $75 \%$ of the metastatic sites, and the lung is the second-most common area of breast cancer metastasis. [13,14] Although the liver is a common metastatic region, only $4 \%-5 \%$ of patients have single liver metastases. Treatment options are usually palliative, and median survival is 4-33 months for patients with liver metastases.[15] A prospective study involving 81 patients has reported that R0 lung resection (81.5\% of patients) was associated with the longer median OS than R1/R2 resections (103.4 vs. 23.6 vs. 20.2 months, respectively; $\mathrm{p}<$ $0.001)$. Size $(>3 \mathrm{~cm}), \mathrm{R} 0$ resection, number $(>2)$, and hormone receptor positivity of metastases were shown to be independent prognostic factors for survival via multivariate analysis.[16] In our study, lung and liver metastases were observed in $16.2 \%$ of patients, and their 5-year OS was 13 months.

Some studies have reported that several patients who had attained complete remission after chemotherapy remained in this condition for extended periods of time, with some in remission for over 20 years in clinical practice. $[17,18]$ These survivors are usually young, have good performance status, and have limited numbers of metastases; however, this describes a numerically small group of patients ( $1 \%$ and $3 \%)$. Furthermore, these findings challenge the commonly held belief that metastatic breast cancer is fatal. Age $\leq 50$, the number of metastatic lesions (1-2 metastases) and systemic chemotherapy administration were found to be significant prognostic factors in univariate analysis in our study. Age $\leq 50$ and systemic chemotherapy administration were found to be independent significant prognostic factors that positively influenced OS like that study.

Local radiotherapy should be administered to patients with good prognostic factors. Patients who may benefit from local radiotherapy include patients with young age, good performance status, ER (+) disease, and $\mathrm{OMBC}$ with $<5$ metastatic lesions.[19] In the present study, the number of metastatic lesions (1-2 metastases), estrogen receptor positivity, age $\leq 50$ and perform radiotherapy to breast or chest wall after surgery was found to be a significant prognostic factor in univariate analysis. However, the multivariate analysis radiotherapy was not a prognostic factor. This is because the number of patients who do not receive radiotherapy is small. A recent study has reported fairly positive findings of a phase II study using SBRT or IMRT for oligometastases from breast cancer.[20] Their study included 23 cases of lymph node metastases that were treated without serious toxicity; however, the major region of metastatic disease was the bone, as in our study.

Local therapy, along with systemic therapy, contributes to OS in patients with OMBC. Providing longterm local control with radiotherapy to the metastatic region extends OS. A study has reported that with the addition of systemic treatment, approximately $73 \%$ of new metastases were prevented from growing.[21] Another study has demonstrated a superior prognosis for treatments using aggressive local therapies, achieving OS rates of $82 \%$ at 10 years and $53 \%$ at 20 years in patients with OMBC.[22] Furthermore, a study has demonstrated that high-dose radiotherapy for treating limited metastases is associated with better OS; [23] however, a limited number of patients with M1 breast cancer are suitable candidates for more aggressive systemic and locoregional treatments.[24] Our study has some limitations. First, this study was a retrospective study. Second, most of our patients had only bone metastases.

\section{Conclusion}

In conclusion, treatment for $\mathrm{OMBC}$ should not be the only palliative. The current treatment approach for patients with metastatic breast cancer is to achieve an asymptomatic extended life. Survival is prolonged via the use of systemic therapies, and local therapies are of importance. Our data present that in some groups of 
patients with $\mathrm{OMBC}$, an aggressive multidisciplinary approach involving both local and systemic treatment may provide long-term disease control and better OS.

\author{
Abbreviations: \\ OMBC: Oligometastatic Breast Cancer \\ OS: Overall Survival \\ MRM: Modified Radical Mastectomy \\ BCS: Breast-conserving Surgery \\ ER: Estrogen Receptor \\ PR: Progesterone Receptor \\ SBRT/SABR: Stereotactic Body Radiation Therapy/ \\ Stereotactic Ablative Radiotherapy \\ IMRT: Intensity-modulated Radiation Therapy
}

Peer-review: Externally peer-reviewed.

Conflict of Interest: The authors declare that they have no conflict of interest.

Ethics Committee Approval: This study was approved by the local ethics committee of the University of Health Science, Istanbul Training and Research Hospital, Turkey (approval number: 2019/1893).

Financial Support: Financial support was not recevied.

Authorship contributions: Concept - Ö.M., D.C.T.; Design - Ö.M., E.A.; Supervision - Ö.M., M.A.N.; Funding - None; Materials - D.C.T., E.A.; Data collection and/or processing - Ö.M., M.A.N.; Data analysis and/or interpretation - Ö.M., D.C.T.; Literature search - Ö.M., E.A.; Writing - Ö.M.; Critical review - Ö.M., M.A.N.

\section{References}

1. Eng LG, Dawood S, Sopik V, Haaland B, Tan PS, BhooPathy N, et al. Ten-year survival in women with primary stage IV breast cancer. Breast Cancer Res Treat 2016;160(1):145-52.

2. Pagani O, Senkus E, Wood W, Colleoni M, Cufer T, Kyriakides $\mathrm{S}$, et al. International guidelines for management of metastatic breast cancer: can metastatic breast cancer be cured? J Natl Cancer Inst 2010;102(7):456-63.

3. Cardoso F, Senkus E, Costa A, Papadopoulos E, Aapro $\mathrm{M}$, André F, et al. 4th ESO-ESMO international consensus guidelines for Advanced Breast Cancer (ABC 4). Ann Oncol 2018;29:1634-57.

4. Hanrahan EO, Broglio KR, Buzdar AU, Theriault RL, Valero V, Cristofanilli $\mathrm{M}$, et al. Combined-modality treatment for isolated recurrences of breast carcinoma: update on 30 years of experience at the University of Texas M.D. Anderson Cancer Center and assessment of prognostic factors. Cancer 2005;104(6):1158-71.
5. Carmichael AR, Anderson EDC, Chetty U, Dixon JM. Does local surgery have a role in the management of stage IV breast cancer? Eur J Surg Oncol 2003;29:17-9.

6. Gnerlich J, Jeffe DB, Deshpande AD, Beers C, Zander C, Margenthaler JA. Surgical removal of the primary tumor increases overall survival in patients with metastatic breast cancer: analysis of the 1988-2003 SEER data. Ann Surg Oncol 2007;14:2187-94.

7. Blanchard DK, Bhatia P, Hilsenbeck SG, Elledge RM. Does surgical management of stage IV breast cancer affect outcome?. Breast Cancer Res Treat 2006;100(Suppl 1):118-9.

8. Eisenhauer EA, Therasse P, Bogaerts J, Schwartz, LH, Sargent D, Ford R, et al. New response evaluation criteria in solid tumours: revised RECIST guideline (version 1.1) Eur J Cancer 2009;45:228-47.

9. Lau WF, Binns DS, Ware RE, Ramdave S, Cachin F, Pitman AG, et al. Clinical experience with the first combined positron emission tomography/computed tomography scanner in Australia. Med J Aust 2005;182(4):172-6.

10. Soran A, Ozmen V, Ozbas S, Karanlik H, Muslumanoglu M, Igci A, et al. A randomized controlled trial evaluating resection of the primary breast tumor in women presenting with de novo stage IV breast cancer: Turkish Study (Protocol MF07-01). 2016 ASCO pubs. Journal of Clinical Oncology 2016;34:(15_ suppl)1005.

11. Hu Q, Zhong X, Liu X, Xie Y, Hu K, He P, Lu D, et al. Resection of primary lesion for patients with metastatic breast cancer: where are we now? Chin Clin Oncol 2018;7(3):24.

12. Coombe R, Lisy K, Campbell J, Perry G, Prasannan S. Survival outcomes following aggressive treatment of oligometastatic breast cancer: a systematic review protocol. JBI Database System Rev Implement Rep 2017;15(8):2013-9.

13. Xiong Z, Deng G, Huang X, Li X, Xie X, Wang J, et al. Bone metastasis pattern in initial metastatic breast cancer: a population-based study. Cancer Manag Res 2018;10:287-95.

14. Smid M, Wang Y, Zhang Y, Sieuwerts AM, Yu J, Klijn JG, et al. Subtypes of breast cancer show preferential site of relapse. Cancer Res 2008;68(9):3108-14.

15. van Walsum GA, de Ridder JA, Verhoef C, Bosscha K, van Gulik TM, Hesselink EJ, et al. Resection of liver metastases in patients with breast cancer: survival and prognostic factors. Eur J Surg Oncol 2012;38(10):910-7.

16. Meimarakis G, Rüttinger D, Stemmler J, Crispin A, Weidenhagen R, Angele M, et al. Prolonged overall survival after pulmonary metastasectomy in patients with breast cancer. Ann Thorac Surg 2013;95(4):117080 . 
17. Tomiak E, Piccart M, Mignolet F, Sahmoud T, Paridaens R, Nooy M, et al. Characterisation of complete responders to combination chemotherapy for advanced breast cancer: a retrospective EORTC Breast Group study. Eur J Cancer 1996;32A(11):1876-87.

18. O'Shaughnessy J. Extending survival with chemotherapy in metastatic breast cancer. Oncologist 2005;10:20-9.

19. Bourgier C, Khodari W, Vataire AL, Pessoa EL, Dunant $\mathrm{A}$, Delaloge $\mathrm{S}$, et al. Breast radiotherapy as part of loco-regional treatments in stage IV breast cancer patients with oligometastatic disease. Radiother Oncol 2010;96(2):199-203.

20. Trovo M, Furlan C, Polesel J, Fiorica F, Arcangeli S, Giaj-Levra N, et al. Radical radiation therapy for oligometastatic breast cancer: Results of a prospective phase II trial. Radiother Oncol 2018;126(1):177-80.
21. Milano MT, Katz AW, Okunieff P. Patterns of recurrence after curative-intent radiation for oligometastases confined to one organ. Am J Clin Oncol 2010;33(2):157-63.

22. Kobayashi T, Ichiba T, Sakuyama T, Arakawa Y, Nagasaki E, Aiba K, et al. Possible clinical cure of metastatic breast cancer: lessons from our 30-year experience with oligometastatic breast cancer patients and literature review. Breast Cancer 2012;19(3):218-37.

23. Yoo GS, Yu JI, Park W, Huh SJ, Choi DH. Prognostic factors in breast cancer with extracranial oligometastases and the appropriate role of radiation therapy. Radiat Oncol J 2015;33(4):301-9.

24. Nguyen DH, Truong PT, Walter CV, Hayashi E, Christie JL, Alexander C. Limited M1 disease: a significant prognostic factor for stage IV breast cancer. Ann Surg Oncol 2012;19:3028-34. 